\title{
MULTI-OBJECTIVE OPTIMIZATION OF A R744/R134A CASCADE REFRIGERATION SYSTEM: EXERGETIC, ECONOMIC, ENVIRONMENTAL, AND SENSITIVE ANALYSIS (3ES)
}

\author{
M.M. Keshtkar ${ }^{1 \star}$, P. Talebizadeh ${ }^{1}$
}

\begin{abstract}
This work presents the optimization of a two stage-cascade refrigeration system (TS-CRS), based on exergetic, economic, environmental, and sensitive analysis (3ES). R134a and R744 are considered as the refrigerants of high and low temperature circuits, respectively. Two single-optimization strategies including exergetic and economic optimizations and a multi-objective optimization are applied on the problem. In the first step, a comprehensive performance evaluation of different effective parameters, based on the genetic algorithm, used to indicate the optimum operative conditions in single objective strategies. In the next step, a multiobjective optimization is performed with considering a decision-making strategy based on the Pareto frontier using TOPSIS method. The higher exergetic efficiency and lower cost found in the exergetic and economic single-optimization, respectively. The multi-objective optimization results demonstrate that, the total system cost and the exergetic efficiency increase $28.6 \%$ and $99.5 \%$, respectively, compared to the base design, and $46.6 \%$ higher energy can be saved in the compressors.
\end{abstract}

\section{Keywords: Cascade Refrigeration, Thermo-economic Optimization, Exergetic, Economic, Environmental, Sensitive Analysis}

\section{INTRODUCTION}

The cascade refrigeration system (CRS) is a freezing system that uses two kinds of refrigerants having different boiling points, which circulate through their own independent refrigeration cycle and are thermally coupled with each other through a cascade condenser [1]. This system is employed to obtain temperatures of -40 to $-80^{\circ} \mathrm{C}$ or ultra-low temperatures [2]. At such ultra-low temperatures, a common single-refrigerant two-stage compression system limits the low-temperature characteristics of the refrigerant to a considerably poor level, making the system significantly inefficient [3]. The efficiency is improved by combining two kinds of refrigerants having different temperature characteristics. Different refrigerants with suitable characteristics for specific applications can be employed in CRSs [4]. Devotta et al. [5] carried out an experimental work based on the replacement of propane (R290) with R22. They concluded that R290 has more COPs and less energy consumption with respect to R22. Chen [6] replaced R22 with R410A in a residential air conditioner and showed an improvement of about $4 \%$ on cooling capacity and $13.9 \%$ on performance coefficient. Lee et al. [7] performed a thermodynamic investigation for a R744-R717 CRS. The optimal condensing temperature was obtained with the aim of maximizing the $\mathrm{COP}$ and minimizing the exergy destruction for the cascade condenser. Bhattacharyya et al. [8] studied a cascade cycle and determined the optimum intermediate temperature for R744/R290. Mafi et al. [9] performed an exergy analysis for multistage CRS and found that the minimum work depends only on the properties of incoming and outgoing process streams cooled or heated with refrigeration system and the ambient temperature.

Another researchers showed that, thermodynamic optimization is widely used for the optimization of energy systems [10]. Modeling and optimization of R717/R134a ice thermal energy storage air conditioning systems using two multi-objective optimization algorithms (NSGA-II and MOPSO) studied by Rahdar et al. [11]. The optimal design parameters which lead to the optimal objective functions (exergy efficiency and total cost rate) achieved. By using TOPSIS decision-making method, the optimum point from Pareto frontier of each optimization algorithm selected for both refrigerants. Najjar et al. [12] carried out a thermoeconomic analysis by combining the energy and exergy analysis with economic analysis to evaluate the total operating cost on a novel 
inlet air cooling system with gas turbine engines using cascaded waste-heat recovery. In this work, a thermoeconomic analysis was done using specific exergy costing method by combining the energy and the exergy analysis with the economic analysis to evaluate the total operating cost of the system over a wide range of operating variables. Rezayan and Behbahaninia [13] studied a thermo-economic optimization of a R744/R717 cascade refrigeration cycle. The optimum values were calculated based on a trade-off between the capital and input exergy costs. Raja et al. [14] used a multiobjective heat transfer search (MOHTS) algorithm and investigated thermo-economic and thermodynamic optimization of a plate-fin heat exchanger. Effectiveness and accuracy of the proposed algorithm were evaluated by analyzing application examples of a PFHX. The obtained results using the proposed algorithm for thermo-economic considerations were compared with the NSGA-II and TLBO. Dubey et al. [15] performed a thermodynamic optimization of a transcritical R744/R1270cycle for heating and cooling applications. Parekh et al. [16] studied a thermo-economic and cost optimizations using R404A-R508B and determined the cost of the products. Keshtkar [17] modeled and optimized a R744/R717 cascade refrigeration system using multi-objective optimization. Toghyani et al. [18] investigated the efficiency and the power loss due to pressure drop into the heat exchangers for a Stirling system using non-ideal adiabatic analysis and the second-version Non-dominated Sorting Genetic Algorithm. The optimized answers were chosen from the results using three decision-making methods. There are some other works in the literature that studied the optimization of thermal systems [19-22].

At this work, the optimum operative condition of a R744-R134a TS-CRS has been evaluated based on thermo-economic performance using genetic algorithm and TOPSIS decision-making procedure with Pareto frontier. For this purpose, an exergy investigation has been performed based on thermo-economic analysis. Then, two different optimization strategies according to exergy, economic and a multi-objective optimization as equilibrium between cost and exergetic optimizations have been carried out. Various parameters of the system including evaporating and condensing temperatures as well as the superheating and sub-cooling degrees of both stages have been optimized. Exergetic, economic, environmental, and sensitive analyses (3ES) have not been carried out so far for R134a/R744 cascade refrigeration system.

\section{MATERIAL AND METHOD}

Figure 1 and Figure 2 display a schematic diagram of a CRS using R744/R134a as the refrigerants and the corresponding $\mathrm{P}-\mathrm{h}$ diagram, respectively. The R134a and R744 are the working fluid of higher and lower stage cycles, respectively. A detailed description of the circuits has been expressed in [19]; however, the difference is using the R134a as a higher stage working fluid in the current study. The basic design parameters used as a case study for the CRS have been listed in Table 1.

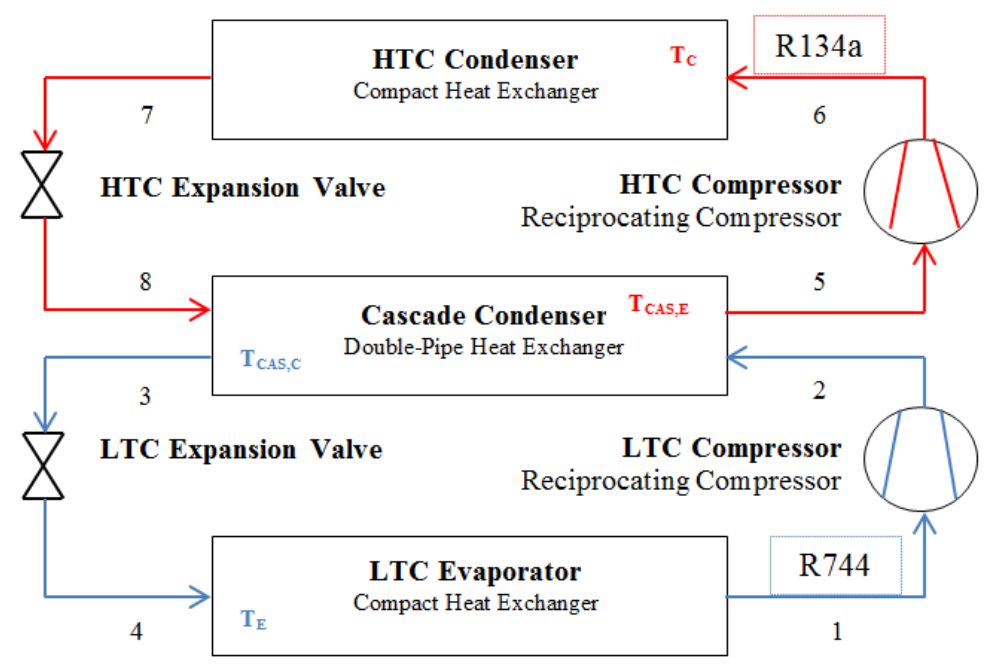

Figure 1. Schematic diagram of R744/R134a system. 


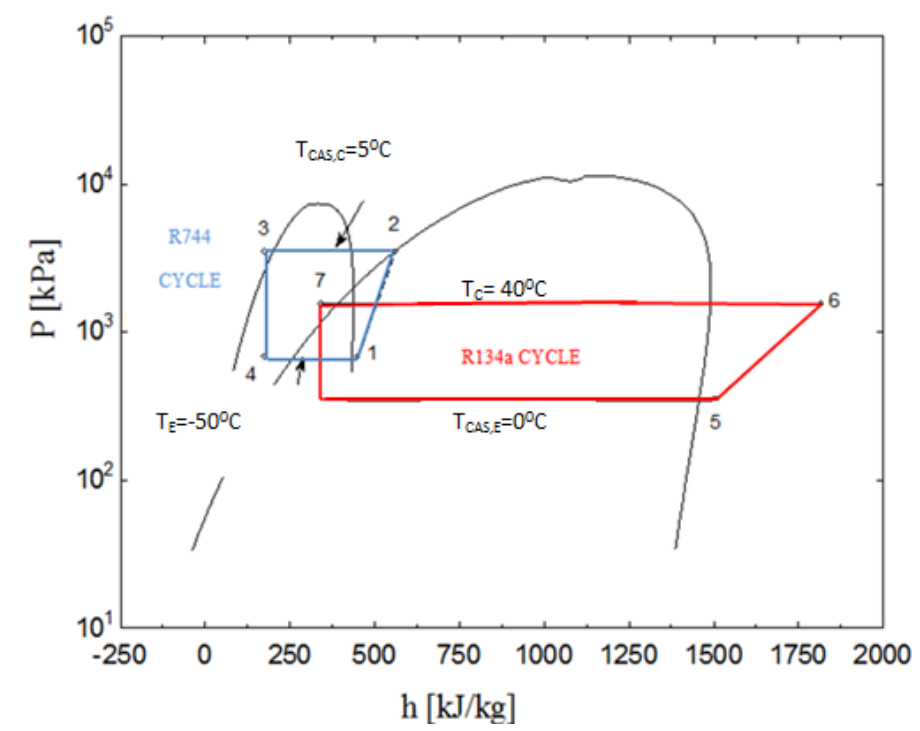

Figure 2. Pressure-enthalpy diagram of R744/R134a CRS.

Table 1. Input parameters used for simulation of CRS at a basic design

\begin{tabular}{|l|c|}
\hline Refrigeration capacity $\left(\dot{Q}_{L}\right)$ & $60 \mathrm{~kW}$ \\
\hline Condensing temperature $\left(T_{C}\right)$ & $40^{\circ} \mathrm{C}$ \\
\hline Evaporating temperature $\left(T_{E}\right)$ & $-50^{\circ} \mathrm{C}$ \\
\hline Temperature difference in cascade condenser $\left(\Delta T_{\text {Cas.cond }}\right)$ & $5^{\circ} \mathrm{C}$ \\
\hline Ambient temperature $\left(T_{0}\right)$ & $26^{\circ} \mathrm{C}$ \\
\hline Cold room temperature $\left(T_{C L}\right)$ & $-27^{\circ} \mathrm{C}$ \\
\hline
\end{tabular}

The following assumptions have been taken into account:

- Considering sub-cooled liquid state for the condenser and cascade condenser outlet conditions at LT circuit.

- Considering superheated vapor state for the evaporator and cascade condenser outlet conditions at HT circuit.

- Considering the adiabatic condition for the compression process within compressor

- Considering the values of $\eta_{m} \eta_{e}$ and $\eta_{s}$ for the HTC and LTC compressors equal to 0.93 and 0.73 , respectively.

- Negligible heat transfer between the heat exchangers and the ambient.

- Considering isenthalpic condition for the throttling process within expansion valve.

- Neglecting the pressure drop in pipelines and heat exchangers.

\section{Energy and Exergy Analysis}

For energy and exergy study of CRS, the needed equations have been specified in Table 2. In addition, the performance coefficient is given as:

$$
\mathrm{COP}=\frac{\dot{\mathrm{Q}}_{\mathrm{E}}}{\dot{\mathrm{W}}_{\mathrm{HTC}}+\dot{\mathrm{W}}_{\mathrm{LTC}}}=\frac{\left(\mathrm{h}_{5}-\mathrm{h}_{8}\right)\left(\mathrm{h}_{1}-\mathrm{h}_{4}\right)}{\left(\mathrm{h}_{6}-\mathrm{h}_{5}\right)\left(\mathrm{h}_{2}-\mathrm{h}_{3}\right)+\left(\mathrm{h}_{5}-\mathrm{h}_{8}\right)\left(\mathrm{h}_{2}-\mathrm{h}_{1}\right)}
$$


The total inlet exergy to the system is given as [23]:

$$
\dot{\mathrm{E}} \mathrm{x}_{\mathrm{in}}=\dot{\mathrm{W}}_{\mathrm{LTC}, \text { comp }}+\dot{\mathrm{W}}_{\mathrm{HTC}, \text { comp }}+\dot{\mathrm{W}}_{\text {fan,evap }}+\dot{\mathrm{W}}_{\text {fan,cond }}
$$

The outlet exergy (exergy of products) can be determined as:

$$
\dot{\mathrm{E}} \mathrm{x}_{\text {out }}=\left(\frac{\mathrm{T}_{0}}{\mathrm{~T}_{\mathrm{CL}}}-1\right) \dot{\mathrm{Q}}_{\mathrm{L}}
$$

The overall system exergy destruction and exergetic efficiency are given as [24]:

$$
\begin{gathered}
\dot{\mathrm{E}} \mathrm{x}_{\mathrm{D}, \text { total }}=\dot{\mathrm{E}} \mathrm{x}_{\text {in }}-\dot{\mathrm{E}} \mathrm{x}_{\text {out }} \\
\eta_{\text {II }}=\frac{\dot{\mathrm{E}} \mathrm{x}_{\text {out }}}{\dot{\mathrm{E}} \mathrm{x}_{\text {in }}}=1-\left(\frac{\dot{\mathrm{E}} \mathrm{x}_{\mathrm{D}, \text { total }}}{\dot{\mathrm{E}} \mathrm{x}_{\text {in }}}\right)
\end{gathered}
$$

\begin{tabular}{|c|c|c|}
\hline Component & Energy Balance & Exergy Balance \\
\hline Evaporator & $\dot{\mathrm{Q}}_{\mathrm{L}}=\dot{\mathrm{m}}_{\mathrm{L}}\left(\mathrm{h}_{1}-\mathrm{h}_{4}\right)$ & 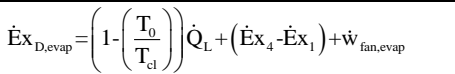 \\
\hline LTC compressor & $\dot{\mathrm{W}}_{\mathrm{LTTCC \text {Comp }}}=\frac{\dot{\mathrm{m}}_{\mathrm{L}}\left(\mathrm{h}_{2 \mathrm{~s}}-\mathrm{h}_{1}\right)}{\eta_{\mathrm{s}} \eta_{\mathrm{m}} \eta_{\mathrm{e}}}=\frac{\dot{\mathrm{m}}_{\mathrm{L}}\left(\mathrm{h}_{2}-\mathrm{h}_{1}\right)}{\eta_{\mathrm{m}} \eta_{\mathrm{e}}}$ & $\dot{\mathrm{E}} \mathrm{x}_{\mathrm{D}, \mathrm{LTC}, \mathrm{comp}}=\left(\dot{\mathrm{Ex}}_{1}-\dot{\mathrm{Ex}}_{2}\right)+\dot{\mathrm{W}}_{\mathrm{LTC}, \mathrm{comp}}$ \\
\hline $\begin{array}{l}\text { HTC compressor } \\
\text { condenser }\end{array}$ & $\dot{\mathrm{W}}_{\text {HTC,Comp }}=\frac{\dot{\mathrm{m}}_{\mathrm{H}}\left(\mathrm{h}_{6 \mathrm{~s}}-\mathrm{h}_{5}\right)}{\eta_{\mathrm{s}} \eta_{\mathrm{m}} \eta_{\mathrm{e}}}=\frac{\dot{\mathrm{m}}_{\mathrm{H}}\left(\mathrm{h}_{6}-\mathrm{h}_{5}\right)}{\eta_{\mathrm{m}} \eta_{\mathrm{e}}}$ & $\dot{\mathrm{Ex}}_{\mathrm{D}, \mathrm{LTC}, \text { comp }}=\left(\dot{\mathrm{Ex}}_{1}-\dot{\mathrm{E}} \mathrm{x}_{2}\right)+\dot{\mathrm{W}}_{\mathrm{LTC}, \mathrm{comp}}$ \\
\hline Cascade condenser & $\dot{\mathrm{Q}}_{\text {Cas cond }}=\dot{\mathrm{m}}_{\mathrm{L}}\left(\mathrm{h}_{2}-\mathrm{h}_{3}\right)=\dot{\mathrm{m}}_{\mathrm{H}}\left(\mathrm{h}_{5}-\mathrm{h}_{8}\right), \quad \frac{\dot{\mathrm{m}}_{\mathrm{H}}}{\dot{\mathrm{m}}_{\mathrm{L}}}=\frac{\mathrm{h}_{2}-\mathrm{h}_{3}}{\mathrm{~h}_{5}-\mathrm{h}_{8}}$ & $\dot{\mathrm{Ex}}_{\mathrm{D}, \mathrm{Cascond}}=\left(\left(\dot{\mathrm{Ex}}_{2}+\dot{\mathrm{E}} \mathrm{x}_{8}\right)-\left(\dot{\mathrm{Ex}}_{3}+\dot{\mathrm{E}} \mathrm{x}_{5}\right)\right)$ \\
\hline $\begin{array}{l}\text { Condenser } \\
\text { LTC expansion valve } \\
\text { HTC expansion valve }\end{array}$ & $\begin{array}{l}\dot{\mathrm{Q}}_{\mathrm{H}}=\dot{\mathrm{m}}_{\mathrm{H}}\left(\mathrm{h}_{6}-\mathrm{h}_{7}\right) \\
\mathrm{h}_{3}=\mathrm{h}_{4} \\
\mathrm{~h}_{7}=\mathrm{h}_{8}\end{array}$ & $\begin{array}{l}\dot{\mathrm{Ex}}_{\mathrm{D}, \text {,ond }}=\left(\frac{\mathrm{T}_{0}}{\mathrm{~T}_{0}}-1\right) \dot{\mathrm{Q}}_{\mathrm{H}}+\left(\dot{\mathrm{Ex}}_{6}-\dot{\mathrm{Ex}}_{7}\right)+\dot{\mathrm{W}}_{\text {fan,cond }} \\
\dot{\mathrm{E} \mathrm{x}_{\mathrm{D}, \mathrm{LTT}, \mathrm{exp}}}=\left(\dot{\mathrm{Ex}}_{3}-\dot{\mathrm{Ex}}_{4}\right) \\
\dot{\mathrm{Ex}}_{\mathrm{D}, \mathrm{HTC}, \mathrm{exp}}=\left(\dot{\mathrm{Ex}}_{7}-\dot{\mathrm{Ex}}_{8}\right)\end{array}$ \\
\hline
\end{tabular}

Table 2. Energy and exergy study of CRS components

\section{Thermo-economic Analysis}

Thermo-economic is the combination of exergy analysis with economic constraints. For an energy system, the thermo-economic analysis allows one to calculate the cost rate of all streams based on thermodynamic and economic analysis. In thermo-economic analysis, all of the stream costs are determined through the exergy costing principles [25]. The exergy costing equation includes the cost balances for every component. For $\mathrm{m}^{\text {th }}$ component, a cost balance indicates that the total cost values related to all streams is identical to the total cost of all streams entering and the suitable charge because of annual capital $\operatorname{cost}\left(\dot{z}_{m}^{C I}\right)$, maintenance cost and annual operating $\left(\dot{z}_{m}^{O M}\right)$, and annual penalty cost $\left(\dot{z}_{m}^{E N V}\right)$ in terms of US\$ per year. Note that in this analysis, as mentioned, the input exergy cost of each component is equal to the output rate of previous component. Therefore, the unknown quantity in the equation is the product's exergy cost. The system's total cost is given as [25]: 


$$
\dot{\mathrm{C}}_{\text {total }}=\sum \mathrm{c}_{\text {out }} \dot{\mathrm{E}} \mathrm{x}_{\text {out }}+\mathrm{c}_{\mathrm{w}} \dot{\mathrm{W}}=\sum \mathrm{c}_{\text {in }} \dot{\mathrm{E} \mathrm{x}_{\text {in }}}+\mathrm{c}_{\mathrm{Q}} \dot{\mathrm{E}} \mathrm{x}_{\mathrm{Q}}+\sum_{\mathrm{m}} \dot{\mathrm{Z}}_{\mathrm{m}}
$$

In Eq. (6), the place of heat and work can change as production or input according to the system conditions. In the exergy costing equation, $\dot{C}_{\text {total }}$ is the sum yearly cost of the system; $c_{i}$ and $c_{o}$ are the unit costs of the input and product exergy, respectively. $\dot{E} x_{i n}$ and $\dot{E} x_{\text {out }}$ are the annual exergy rates from internal sources and output products, respectively. In TS-CRS, the input exergy is only the electrical energy, while the product is cooling capacity. The capital cost of each component $\left(z_{m}^{C I}\right)$ is given as [26]:

$$
\begin{gathered}
\mathrm{Z}_{\mathrm{HTC}, \text { comp }}=9624.2 \dot{\mathrm{W}}_{\mathrm{HTC}, \text { comp }}^{0.46} \\
\mathrm{Z}_{\mathrm{LTC, \text {comp }}}=10167.5 \dot{\mathrm{W}}_{\mathrm{LTC, \text {comp }}}^{0.46} \\
\mathrm{Z}_{\text {cond }}=1397 \mathrm{~A}_{\text {cond }}^{0.89}+629.05 \dot{\mathrm{W}}_{\text {fan,cond }}^{0.76} \\
\mathrm{Z}_{\text {evap }}=1397 \mathrm{~A}_{\text {evap }}{ }^{0.89}+629.05 \dot{\mathrm{W}}_{\text {fan,evap }}^{0.76} \\
\mathrm{Z}_{\text {cas,cond }}=2382.9 \mathrm{~A}_{\text {cas,cond }}^{0.68}
\end{gathered}
$$

In engineering economics, by introducing the capital recovery factor (CRF), the time interval unit considered for the capital cost calculation is commonly considered as a year and determined as [25]:

$$
\mathrm{CRF}=\frac{\mathrm{i}(1+\mathrm{i})^{\mathrm{n}}}{(1+\mathrm{i})^{\mathrm{n}}-1}
$$

At the present work, the rate of interest $(i)$ and the system life $(n)$ are assumed $14 \%$ and 15 years, respectively. According to the investment $\operatorname{cost} z_{m}(\$)$, the common function for the cost rate, $\dot{\mathrm{z}}_{m}(\$ / \mathrm{s})$, related to capital cost and the maintenance cost for the $m^{\text {th }}$ is given as:

$$
\dot{\mathrm{Z}}_{\mathrm{m}}=\frac{\mathrm{Z}_{\mathrm{m}} \times \mathrm{CRF} \times \mathrm{f}}{\mathrm{N} \times 3600}
$$

At this work, the values of the maintenance factor $(\phi)$, the system yearly hours of operation $(N)$, and $C R F$ are considered $1.06,8000 \mathrm{~h}$ and $18.2 \%$, respectively. After obtaining the cost rate for all components, the total annual cost rate is given as: 


$$
\begin{aligned}
\dot{\mathrm{C}}_{\mathrm{tot}}= & \left(\dot{\mathrm{Z}}_{\mathrm{HTC}, \text { comp }}+\dot{\mathrm{Z}}_{\mathrm{LTC}, \text { comp }}+\dot{\mathrm{Z}}_{\text {cond }}+\dot{\mathrm{Z}}_{\text {evap }}+\dot{\mathrm{Z}}_{\text {cas,cond }}\right)+ \\
& \left(\dot{\mathrm{W}}_{\mathrm{HTC}, \text { comp }}+\dot{\mathrm{W}}_{\mathrm{LTC}, \text { comp }}+\dot{\mathrm{W}}_{\mathrm{Fan}, \mathrm{LTC}}+\dot{\mathrm{W}}_{\mathrm{Fan}, \mathrm{HTC}}\right) \times\left[\frac{1}{3} \frac{\mathrm{c}_{\text {elec,peak }}}{3600}+\frac{2}{3} \frac{\mathrm{c}_{\text {elec,mid-peak }}}{3600}\right]+ \\
& \frac{\left(\mathrm{m}_{\mathrm{Co}_{2}} / 1000\right)}{\mathrm{N}} \times \frac{\mathrm{c}_{\mathrm{Co}_{2}}}{3600}
\end{aligned}
$$

where value of $c_{\text {elec,peak }}$, is $0.07 \$ \mathrm{kWh}^{-1}$, and $c_{\text {elec, mid-peak }}$ is $0.04 \$ \mathrm{kWh}^{-1}$, which are the unit costs of electricity during the working hours for the peak and the mid-peak time, respectively. Note that the $1 / 3$ and $2 / 3$ coefficients show the electricity use in the peak and the mid-peak. $m_{\mathrm{Co}_{2}}(\mathrm{~kg})$ is the amount of $\mathrm{CO}_{2}$ emission and is determined from the annual electricity consumption $[k W h]$, using the emission conversion factor equal to $0.968 \mathrm{~kg} \mathrm{kWh}^{-1}$. At the present work, the unit environmental cost of emission of carbon dioxide $\left(c_{\mathrm{Co}_{2}}\right)$ is assumed 90(US\$/ton $\left.\mathrm{Co}_{2}\right)[26]$.

\section{Heat Exchanger Design}

Since the annual cost of CRS depends on the pressure drop and thermal area of heat exchangers, the design of the employed heat exchangers including evaporator, air-cooled, and cascade condensers is important [27]. Evaporator and air-cooled condenser are compact air-cooled heat exchangers. The cascade condenser is a double-pipe heat exchanger. For designing of heat exchangers, the number of tube rows, tube diameter, and tube thickness are important. At the present work, for heat transfer and pressure drop calculations, the library functions in EES (Engineering Equation Solver) were used [28]. The heat transfer area for every heat exchanger is given as:

$$
\mathrm{A}_{\mathrm{o}}=\dot{\mathrm{Q}} / \mathrm{U}_{\mathrm{o}}(\mathrm{LMTD})
$$

The overall coefficient of heat transfer $\left(U_{O}\right)$ regarding the external heat transfer area and the logarithmic temperature are given as:

$$
\frac{1}{\mathrm{U}_{\mathrm{o}} \mathrm{A}_{\mathrm{o}}}=\frac{1}{\mathrm{~h}_{\mathrm{i}} \mathrm{A}_{\mathrm{i}}}+\frac{1}{\mathrm{~h}_{\mathrm{o}} \mathrm{A}_{\mathrm{o}}}+\frac{\ln \left(\mathrm{d}_{\mathrm{o}} / \mathrm{d}_{\mathrm{i}}\right)}{2 \pi \mathrm{Lk}}, \quad \mathrm{LMTD}=\frac{\left(\mathrm{T}_{\text {hot } \mathrm{i}}-\mathrm{T}_{\text {cold } \mathrm{o}}\right)-\left(\mathrm{T}_{\text {hot, } \mathrm{o}}-\mathrm{T}_{\text {cold }, \mathrm{i}}\right)}{\ln \frac{\left(\mathrm{T}_{\text {hot }, \mathrm{i}}-\mathrm{T}_{\text {cold } \mathrm{o}}\right)}{\left(\mathrm{T}_{\text {hot }, \mathrm{o}}-\mathrm{T}_{\text {cold }, \mathrm{i}}\right)}}
$$

Figure 3 shows a compact tube-fin, cross-flow heat exchanger used in the present work for the evaporator, and air-cooled condenser. The geometric parameters have been shown in Fig. 3. The fins have been made from copper with a thickness of $t h_{\text {fin }}$ and a fin pitch of $p_{\text {fin }}$. The heat exchanger includes 10 rows of tubes in two columns connected in series. The vertical and horizontal spacing between adjacent tubes is $s_{v}$ and $s_{h}$, respectively. The heat exchanger length in the direction of the airflow is $L$, and the width and height of the front face are $W$ and $H$, respectively. The tubes have been made from copper with outer diameter of $D_{\text {out }}$ and wall thickness, $t h$. The roughness of the tube inner surface is $e=10 \mu \mathrm{m}$. Clean dry air passes through the heat exchanger perpendicular to the tubes with a volumetric flow rate of $\dot{V}_{c}=0.06 \mathrm{~m}^{3} / \mathrm{s}$. Table 3 shows the geometric parameters of the condenser and evaporator. The pressure drop of the air regarding the compact tubefin heat exchanger is given as: 


$$
\Delta \mathrm{p}=\frac{\mathrm{G}^{2}}{2 \rho_{\text {in }}}\left[\mathrm{f} \frac{4 \mathrm{~L}_{\text {flow }}}{\mathrm{D}_{\mathrm{h}}} \frac{\rho_{\text {in }}}{\bar{\rho}}+\left(1+\sigma^{2}\right)\left(\frac{\rho_{\text {in }}}{\rho_{\text {out }}}-1\right)\right], \quad \frac{1}{\bar{\rho}}=\frac{1}{2}\left(\frac{1}{\rho_{\text {in }}}+\frac{1}{\rho_{\text {out }}}\right)
$$

$G$ is mass velocity, and $\rho_{i}, \rho_{o}$, and $\bar{\rho}$ are, the inlet, outlet, and mean air density, respectively. $f$ is the coefficient of friction presented in [29]. More information on the subject of air-side and tube-side pressure drop and heat transfer calculations for all heat exchangers are found at [30-32]. It should be noted that, selection of cascade condenser model has been carried out based on pre-defined models in EES library [28]. At the double-pipe heat exchanger, the fluid in inner pipe is considered R744 and in annual space is R134a.

Table 3. Geometry specifications of evaporator and condenser at this work.

\begin{tabular}{|l|c|c|c|c|c|c|}
\hline Component & $\begin{array}{c}\text { Outside } \\
\text { diameter }(\mathbf{m})\end{array}$ & $\begin{array}{c}\text { Tube thickness } \\
\mathbf{( m m})\end{array}$ & $\begin{array}{c}\text { Fin } \\
\text { thickness } \\
\mathbf{( m m}\end{array}$ & $\begin{array}{c}\text { Horizontal } \\
\text { pitch } \mathbf{( m m})\end{array}$ & $\begin{array}{c}\text { Vertical pitch } \\
\mathbf{( m m})\end{array}$ & $\begin{array}{c}\text { Number of tube } \\
\text { rows }\end{array}$ \\
\hline Evaporator & 0.0102 & 0.9 & 0.33 & 22 & 25.4 & 10 \\
\hline Condenser & 0.0159 & 0.9 & 0.33 & 22 & 25.4 & 10 \\
\hline
\end{tabular}

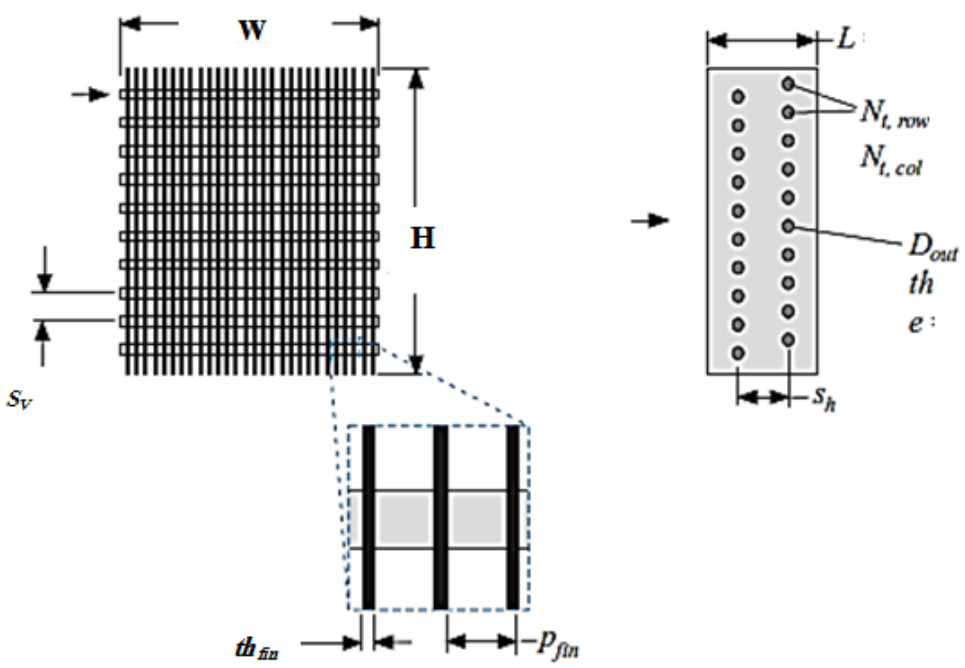

Figure 3. Schematic of evaporator and condenser.

\section{SYSTEM OPTIMIZATION WITH NSGA-II}

For the thermo-economic optimization, six independent parameters have been shown in Table 4. These parameters are chosen as the decision making variables within the defined range. The maximum and minimum values for each design parameter have been applied as the constraints. The loaded optimization limitations of the key design parameters have been indicated according to the proposed rates from the literature [25].

Two different objective functions have been employed as the optimization strategies; the total cost rate $\left(\dot{C}_{t o t}\right)$ and the exergy efficiency $\left(\eta_{I I}\right)$ of CRS. The exergy efficiency represents the thermodynamic irreversibility due to the heat transfer extracted by the variation of temperature in various components. The following multi-linear regression equations are fitted on the EES achieved data:

$$
\begin{gathered}
\eta_{\text {II }}=a_{0}+a_{1} \Delta T_{\text {sub }, \mathrm{H}}+a_{2} \Delta \mathrm{T}_{\text {sub } \mathrm{H}}^{2}+\mathrm{a}_{3} \Delta \mathrm{T}_{\text {sub } \mathrm{L}}+\mathrm{a}_{4} \Delta \mathrm{T}_{\text {sub } \mathrm{L}}^{2}+\mathrm{a}_{5} \Delta \mathrm{T}_{\text {sup } \mathrm{H}}+\mathrm{a}_{6} \Delta \mathrm{T}_{\text {sup }, \mathrm{H}}^{2} \\
+\mathrm{a}_{7} \Delta \mathrm{T}_{\text {sup }, \mathrm{L}}+\mathrm{a}_{8} \Delta \mathrm{T}_{\text {sup } \mathrm{L}}^{2}+\mathrm{a}_{9} \mathrm{~T}_{\mathrm{C}}+\mathrm{a}_{10} \mathrm{~T}_{\mathrm{C}}^{2}+\mathrm{a}_{11} \mathrm{~T}_{\mathrm{E}}+\mathrm{a}_{12} \mathrm{~T}_{\mathrm{E}}^{2}
\end{gathered}
$$




$$
\begin{gathered}
\dot{\mathrm{C}}_{\text {total }}=\mathrm{b}_{0}+\mathrm{b}_{1} \Delta \mathrm{T}_{\text {sub } \mathrm{H}}+\mathrm{b}_{2} \Delta \mathrm{T}_{\text {sub } \mathrm{H}}^{2}+\mathrm{b}_{3} \Delta \mathrm{T}_{\text {sub } \mathrm{L}}+\mathrm{b}_{4} \Delta \mathrm{T}_{\text {sub } \mathrm{L}}^{2}+\mathrm{b}_{5} \Delta \mathrm{T}_{\text {sup } \mathrm{H}}+\mathrm{b}_{6} \Delta \mathrm{T}_{\text {sup } \mathrm{H}}^{2} \\
+\mathrm{b}_{7} \Delta \mathrm{T}_{\text {sup }, \mathrm{L}}+\mathrm{b}_{8} \Delta \mathrm{T}_{\text {sup } \mathrm{L}}^{2}+\mathrm{b}_{9} \mathrm{~T}_{\mathrm{C}}+\mathrm{b}_{10} \mathrm{~T}_{\mathrm{C}}^{2}+\mathrm{b}_{11} \mathrm{~T}_{\mathrm{E}}+\mathrm{b}_{12} \mathrm{~T}_{\mathrm{E}}^{2}
\end{gathered}
$$

The multi-linear regression coefficients for Eqs. (18) and (19) have been given in Table 5. The root mean square errors and coefficients of correlations have been calculated equal to $1.076 \mathrm{E}-03$ and $99.48 \%$ for Eq. (18) and 4.309E-05 and 97.15\% for Eq. (19), respectively [33].

Table 4. Decision variables for TS-CRS and their corresponding range of variation.

\begin{tabular}{|l|c|}
\hline Decision variables & Range of variation \\
\hline Condensing temperature of R134a & $38^{\circ} \mathrm{C}<\mathrm{T}_{\mathrm{C}}<48^{\circ} \mathrm{C}$ \\
\hline Evaporating temperature of $\mathrm{R} 744$ & $-60^{\circ} \mathrm{C}<\mathrm{T}_{\mathrm{E}}<-40^{\circ} \mathrm{C}$ \\
\hline Degree of superheating at R744circuit & $0^{\circ} \mathrm{C}<\Delta \mathrm{T}_{\text {sup, LTC }}<20^{\circ} \mathrm{C}$ \\
\hline Degree of subcooling at R744circuit & $0^{\circ} \mathrm{C}<\Delta \mathrm{T}_{\text {sub, LTC }}<10^{\circ} \mathrm{C}$ \\
\hline Degree of superheating at R134a circuit & $0^{\circ} \mathrm{C}<\Delta \mathrm{T}_{\text {sup, } \mathrm{HTC}}<20^{\circ} \mathrm{C}$ \\
\hline Degree of subcooling at R134a circuit & $0^{\circ} \mathrm{C}<\Delta \mathrm{T}_{\text {sub,HTC }}<10^{\circ} \mathrm{C}$ \\
\hline
\end{tabular}

Table 5. Coefficients of Eqs. (18 and 19) using Multi-linear regression.

\begin{tabular}{|c|c|c|c|c|c|c|c|c|c|c|c|c|c|}
\hline$\eta_{I I}$ & $a_{0}$ & $a_{1}$ & $a_{2}$ & $a_{3}$ & $a_{4}$ & $a_{5}$ & $a_{6}$ & $a_{7}$ & $a_{8}$ & $a_{9}$ & $a_{10}$ & $a_{11}$ & $a_{12}$ \\
\hline Values & $\begin{array}{c}-1.6468 \\
\mathrm{E}+00\end{array}$ & $\begin{array}{c}1.5169 \\
\mathrm{E}+00\end{array}$ & $\begin{array}{c}3.4059 \\
\mathrm{E}-03\end{array}$ & $\begin{array}{c}9.1870 \\
\mathrm{E}-01\end{array}$ & $\begin{array}{c}2.6264 \\
\mathrm{E}-01\end{array}$ & $\begin{array}{c}-1.0013 \\
\mathrm{E}-01\end{array}$ & $\begin{array}{c}-8.2059 \\
\mathrm{E}-03\end{array}$ & $\begin{array}{c}-1.2031 \\
\mathrm{E}+00\end{array}$ & $\begin{array}{c}-9.5615 \\
\mathrm{E}-03\end{array}$ & $\begin{array}{c}1.3121 \\
\mathrm{E}-01\end{array}$ & $\begin{array}{c}3.3807 \\
\mathrm{E}-03\end{array}$ & $\begin{array}{c}-7.8029 \\
\mathrm{E}-04\end{array}$ & $\begin{array}{c}1.6868 \\
\mathrm{E}-03\end{array}$ \\
\hline$\dot{C}_{\text {tot }}$ & $b_{0}$ & $b_{1}$ & $b_{2}$ & $b_{3}$ & $b_{4}$ & $b_{5}$ & $b_{6}$ & $b_{7}$ & $b_{8}$ & $b_{9}$ & $b_{10}$ & $b_{11}$ & $b_{12}$ \\
\hline Values & $\begin{array}{c}5.8974 \\
\mathrm{E}-03\end{array}$ & $\begin{array}{c}-1.1183 \\
\mathrm{E}-04\end{array}$ & $\begin{array}{c}-5.2061 \\
\mathrm{E}-05\end{array}$ & $\begin{array}{c}6.0660 \\
\mathrm{E}-04\end{array}$ & $\begin{array}{c}-1.1655 \\
\mathrm{E}-04\end{array}$ & $\begin{array}{c}2.8431 \\
\mathrm{E}-05\end{array}$ & $\begin{array}{c}1.7375 \\
\mathrm{E}-05\end{array}$ & $\begin{array}{c}-9.5376 \\
\mathrm{E}-05\end{array}$ & $\begin{array}{c}5.0526 \\
\mathrm{E}-05\end{array}$ & $\begin{array}{c}-3.5672 \\
\mathrm{E}-05\end{array}$ & $\begin{array}{c}-4.2426 \\
\mathrm{E}-07\end{array}$ & $\begin{array}{c}-1.2371 \\
\mathrm{E}-04\end{array}$ & $\begin{array}{c}2.2200 \\
\mathrm{E}-06\end{array}$ \\
\hline
\end{tabular}

It is noticeable that for optimization of the system, the exergy efficiency (Eq. 18) should be maximized, while the total cost rate (Eq. 19) should be minimized. To optimization of the CRS, a NSGA-II genetic algorithm method has been used. In engineering optimization, genetic algorithms can establish reasonable solutions with random initialization [34]. Genetic algorithm is a non-deterministic optimization technique with general-purpose search method based on the principles of evolution including the crossover, selection, and mutation operators with the aim of presenting the optimal solution in a population to achieve an identified criterion of termination. The setting parameters in GA optimization method have been given in Table 6 .

Table 6. The setting parameters in the optimization process

\begin{tabular}{|l|r|}
\hline Setting parameters & value \\
\hline Population size & 500 \\
\hline Maximum number of generation & 400 \\
\hline Minimum function tolerance & $10^{-5}$ \\
\hline Probability of crossover & $90 \%$ \\
\hline Probability of mutation & $1 \%$ \\
\hline Number of crossover point & 2 \\
\hline Selection process & 2 \\
\hline Tournament size & Tournament \\
\hline
\end{tabular}

Note that an in-house computer code software has been developed in MATLAB to achieve the Pareto frontier. The Pareto frontier solution indicates the optimal solutions, and one of these solutions is selected as the 
best solution in this work using a decision-making technique. TOPSIS is a decision-making technique for finding the closest result to the ideal solution defined in the following argument.

In this method since the dimension of various objectives might be different, first, the scales and dimension of objectives space must be non-dimensionalized. So, a non-dimensionalized objective, $F_{i j}{ }^{n}$, is introduced as:

$$
\mathrm{F}_{\mathrm{ij}}^{\mathrm{n}}=\frac{\mathrm{F}_{\mathrm{ij}}}{\sqrt[2]{\sum_{\mathrm{i}=1}^{\mathrm{m}}\left(\mathrm{F}_{\mathrm{ij}}\right)^{2}}}
$$

Decision making in the TOPSIS method is performed by calculating each solution's distance on the Pareto frontier from the best point indicated by $d_{i}^{+}$and from the non-ideal point indicated by $d_{i}^{-}$as following [35]:

$$
\begin{aligned}
& d_{i}^{+}=\sqrt{\sum_{j=1}^{n}\left(F_{i j}-F_{j}^{\text {Ideal }}\right)^{2}} \\
& d_{i}^{-}=\sqrt{\sum_{j=1}^{n}\left(F_{i j}-F_{j}^{\text {Non-Ideal }}\right)^{2}}
\end{aligned}
$$

where $n$ shows the objectives; $i$ stands for every solution on the frontier of Pareto $(i=1,2, \ldots, m) . F_{j}^{\text {Ideal }}$ and $F_{j}^{\text {Non-Ideal }}$ are the ideal and non-ideal values for $j_{t h}$ objective calculated from a single-objective optimization, respectively. In the non-ideal point, every objective possesses its worst value. Therefore, a $\mathrm{Cl}_{i}$ variable is also explained as:

$$
C l_{i}=\frac{d_{i}^{-}}{d_{i}^{+}+d_{i}^{-}}
$$

Finally, a solution with minimum $C l_{i}$ is chosen as a suitable solution.

\section{RESULTS AND DISCUSSION}

To find the effect of various parameters on the COP of the system, the exergy destruction value of all components $\left(\dot{E} x_{D}\right)$, the exergetic efficiency $\left(\eta_{I I}\right)$, and the overall system's cost are first analyzed. A sensitive analysis is carried out before the optimization process. The evaporation, condensation, sub-cooling, and superheating temperature in both cycle have been selected as the most effective parameters in CRS cycle. Furthermore, their variations are much more important than other parameters.

Figure 4 shows the effect of evaporating temperature in R134a circuit $\left(T_{C A S, E}\right)$ on the COP of the system at the given operating conditions. Figs.4-a and 4-b display the variation of COP at different values of subcooling and superheating degrees, respectively. It can be seen that the $C O P_{M A X}$ increased as the degree of subcooling increased. Furthermore, increasing the sub-cooling degree from $\Delta T_{\text {sub }}=0$ to $\Delta T_{\text {sub }}=10^{\circ} \mathrm{C}$ enhanced in the $C O P_{M A X}$ from 1.342 to 1.445 , i.e. a $10.3 \%$ increase with respect to its value without sub-cooling. On the 
contrary (Fig. 4-b), increasing the superheating degree from $\Delta T_{\text {sup }}=0$ to $\Delta T_{\text {sup }}=20^{\circ} \mathrm{C}$ decreases the $C O P_{M A X}$ from 1.346 to $1.275(7.1 \%)$.

Figures 5-a and 5-b show the $\mathrm{COP}$ and mass ratio variations as a function of condensing and evaporation temperature and variation in temperature in cascade condenser, respectively. As the temperature in condenser or cascade condenser increases, the COP of the cascade system decreases; however, the elevation in the evaporating temperature results in a rise in the COP of the system. As the condensing temperature in HTC circuit increases, the pressure ratio of the R134a compressor increases, leading to an increase in the electric power in the HTC compressor, and therefore, the COP decreases. As observed in Fig. 5-b, as the evaporating temperature increases, the mass ratio of CRS decreases; however, the rise in condensing temperature causes a higher mass ratio.

The exergy destruction of all components for two cases without sub-cooling and both sub-cooling /superheating for $60 \mathrm{kw}$ cooling load, have been specified in Table 7. As observed in this figure, the condenser has the maximum rate of exergy destruction compared with other components in the cycle.

As listed, condenser has the most exergy destruction in the system, and the evaporator is at the next level. According to the first law of thermodynamic, a significant improvement exists in the condenser. Note that that reducing the sub-cooling causes a higher but negligible effect on exergy destruction values of the components.

Figures 6-a and 6-b show the variation of R744 evaporating temperature, $T_{E}$, on the components' cost for various sub-cooling and superheating values in both cycles. The higher cost of air-cooled condenser was achieved for lower values of $T_{E}$ since the logarithmic temperature variation between the condensation and ambient temperatures decreased. However, the cost of the LT compressor decreased because of the decrease in the LTC pressure ratio. The cost of air-cooled condenser decreased because of a decline in the removed heat from the condenser, and consequently, the cost of cascade condenser increased. Furthermore, the cost of HTC compressor varied very little because of a minor variation in the mass flow rate of R134a circuit. Comparing Figures 6-a and 6-b, the effect of $\Delta T_{\text {sub }}$ and $\Delta T_{\text {sup }}$ on both cycles was clarified. Furthermore, by increasing $\Delta T_{\text {sub }}$ from $0 \mathrm{~K}$ to $8 \mathrm{~K}$ and $\Delta T_{\text {sup }}$ from $10 \mathrm{~K}$ to $20 \mathrm{~K}$, the evaporator cost decreased; however, the condenser and cascade condenser costs increased. Moreover, because of the negligible influence of superheating and subcooling degrees' variations on the compressors, the costs of LT and HT compressors remained constant.

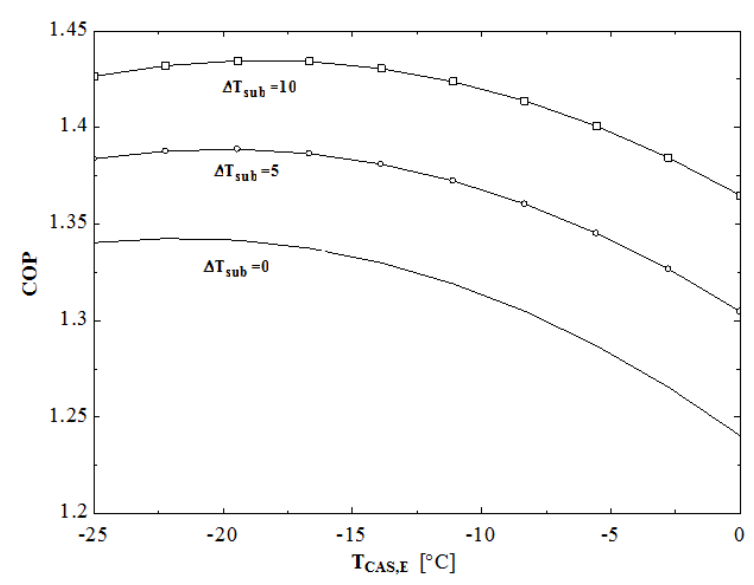

(a)

$$
\left(T_{C}=40^{\circ} \mathrm{C}, T_{E}=-50^{\circ} \mathrm{C}, \Delta T_{\text {Cascond }}=5^{\circ} \mathrm{C}, \Delta T_{\text {sup }}=0^{\circ} \mathrm{C}\right)
$$

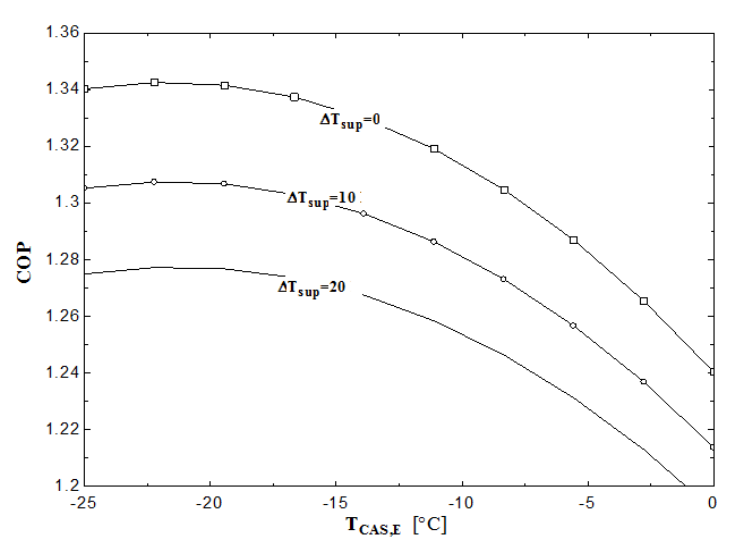

(b)

$$
\left(T_{C}=40^{\circ} \mathrm{C}, T_{E}=-50^{\circ} \mathrm{C}, \Delta T_{\text {Cascond }}=5^{\circ} \mathrm{C}, \Delta T_{\text {sub }}=0^{\circ} \mathrm{C}\right)
$$

Figure 4. Variation of system coefficient performance for different evaporating temperature in HT circuit with considering of (a) subcooling and (b) superheating on both cycles. 


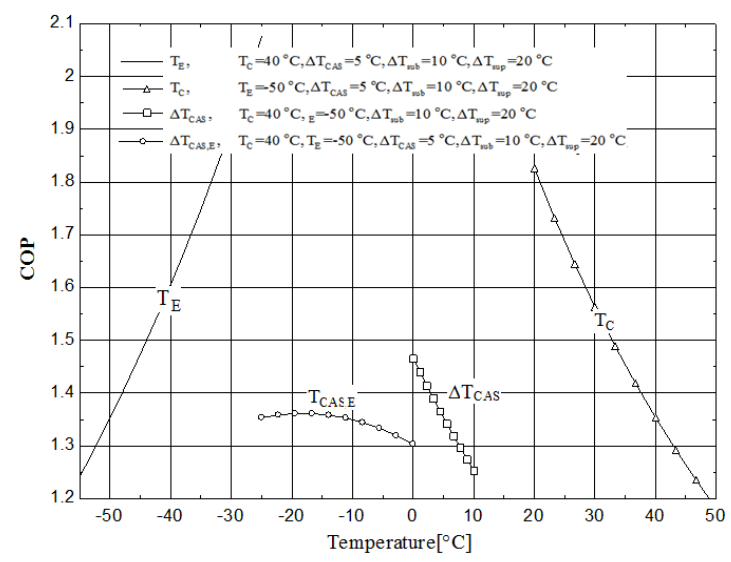

(a)

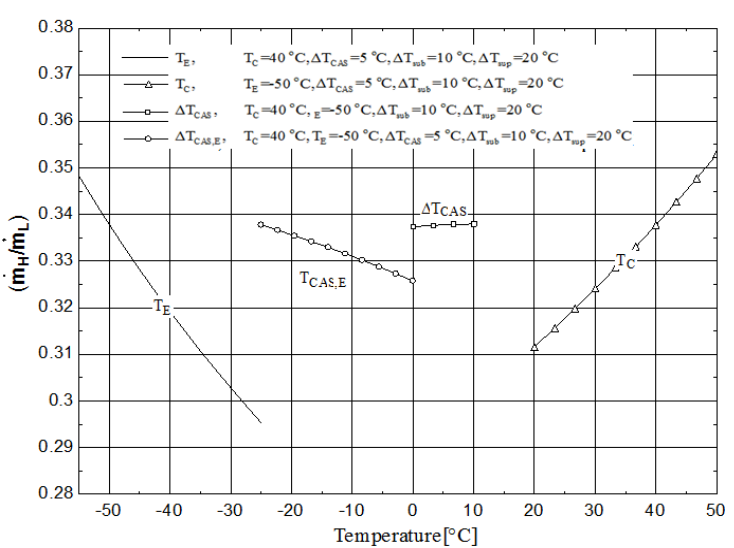

(b)

Figure 5. Effect of evaporating $\left(\mathrm{T}_{\mathrm{E}}\right)$, condensing $\left(\mathrm{T}_{\mathrm{C}}\right)$, evaporating temperature in R134a cycle $\left(\mathrm{T}_{\mathrm{CAS}, \mathrm{E}}\right)$ and temperature difference in cascade condenser $\left(\Delta \mathrm{T}_{\mathrm{CAS}}\right)$ on (a) system performance and (b) mass ratio at various conditions.

Table7. The exergy destruction rates $(k W)$ for cooling load of $60 k w$.

\begin{tabular}{|l|c|c|c|c|c|c|c|}
\hline Component & $\begin{array}{c}\text { HTC } \\
\text { Comp. }\end{array}$ & $\begin{array}{c}\text { LTC } \\
\text { Comp. }\end{array}$ & Condenser & Evaporator & $\begin{array}{c}\text { Cascade } \\
\text { Cond. }\end{array}$ & $\begin{array}{c}\text { HTC } \\
\text { Ex. } \\
\text { Valve }\end{array}$ & $\begin{array}{c}\text { LTC } \\
\text { Ex. } \\
\text { Valve }\end{array}$ \\
\hline$\left(\Delta T_{\text {sub }}=8^{\circ} \mathrm{C}, \Delta T_{\text {sup }}=10^{\circ} \mathrm{C}\right)$ & 2.1 & 2.4 & 10.2 & 5.6 & 0.7 & 0.2 & 0.1 \\
\hline$\left(\Delta T_{\text {sub }}=0^{\circ} \mathrm{C}, \Delta T_{\text {sup }}=10^{\circ} \mathrm{C}\right)$ & 2.3 & 2.6 & 10.7 & 5.9 & 0.85 & 0.25 & 0.15 \\
\hline
\end{tabular}

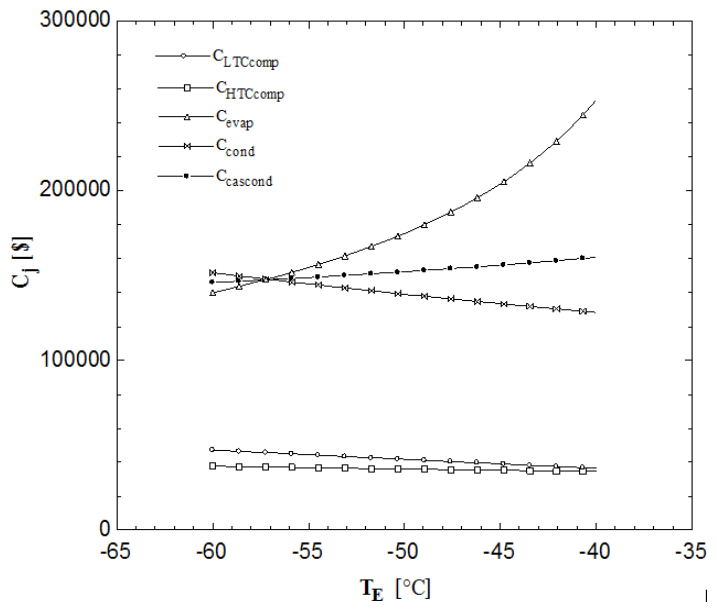

(a) $\Delta T_{\text {sub }}=0, \Delta T_{\text {sup }}=10^{\circ} \mathrm{C}$

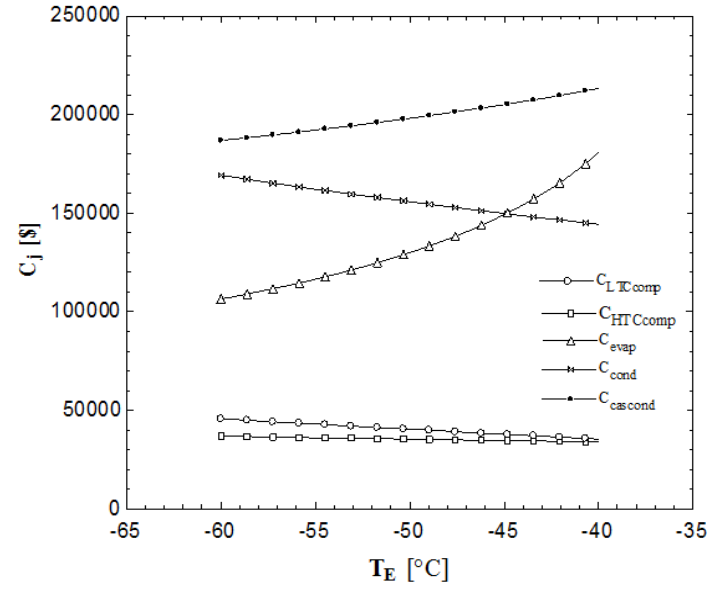

(b) $\Delta T_{\text {sub }}=8^{\circ} \mathrm{C}, \Delta T_{\text {sup }}=20^{\circ} \mathrm{C}$

Figure 6. Effect of R744 evaporating temperature on the costs of system components

$$
\left(T_{C}=40^{\circ} \mathrm{C}, \Delta T_{\text {Cascond }}=5^{\circ} \mathrm{C}, T_{C A S, E}=-5^{\circ} \mathrm{C}\right)
$$

Figures 7-a and 7-b show the variation of $\Delta T_{s u b, L}$ and $\Delta T_{s u b, H}$, i.e. the sub-cooling degrees in low and high temperature circuits on the annual total cost and exergetic efficiency of the CRS. By increasing $\Delta T_{s u b, L}$ or $\Delta T_{s u b, H}$, the exergetic efficiency and annual overall cost rose. Furthermore, an optimum point for sub-cooling degree can be found by carrying out a trade-off between the annual total cost and the system's exergetic efficiency. 
The variations of $\Delta T_{\text {sup }, L}$ and $\Delta T_{\text {sup }, H}$, i.e. the superheating degrees in low and high temperature circuits on the annual total cost and exergetic efficiency of the CRS have been shown in Figs.7-c and 7-d. Increasing $\Delta T_{\text {sup }, L}$ or $\Delta T_{\text {sup }, H}$ decreases the annual total cost and exergetic efficiency. However, comparing Figures 7-c and 7-d, optimum points for superheating degree can be obtained by performing a trade-off between the total cost and exergetic efficiency of the system.

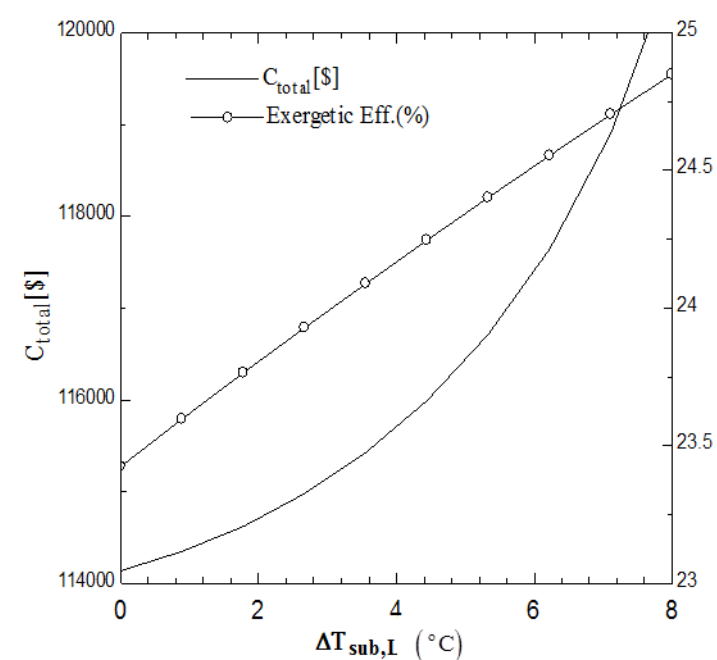

(a)

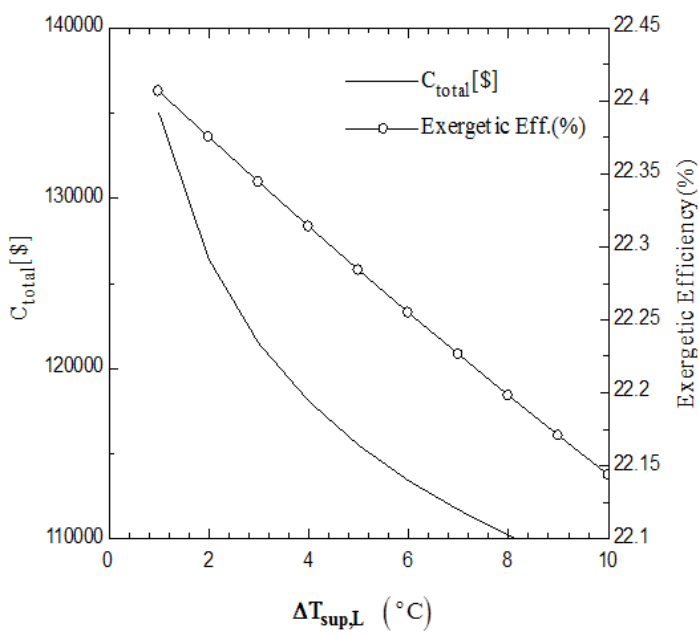

(c)

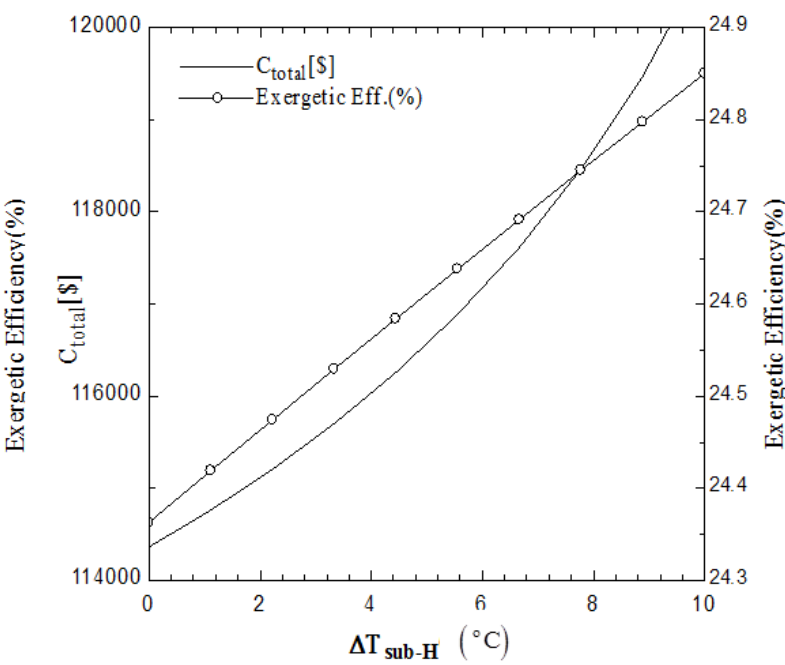

(b)

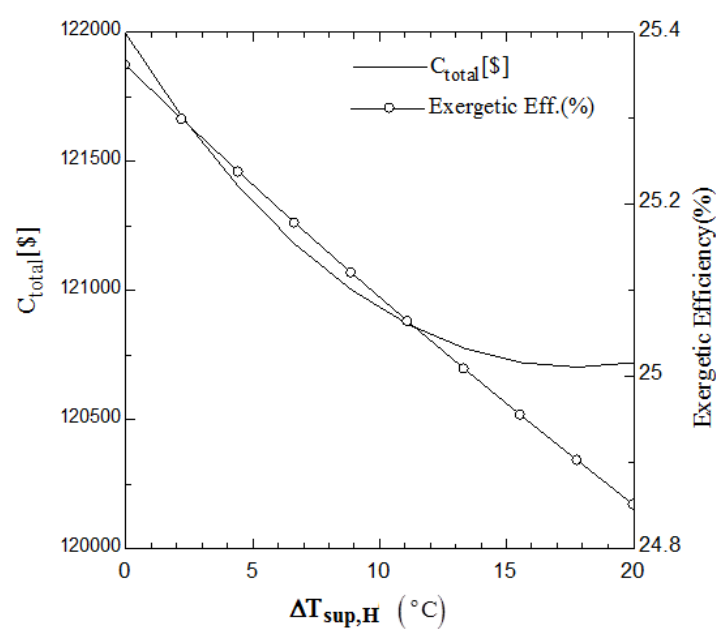

(d)

Figure 7. Variations of annual cost and exergetic efficiency of the system versus the (a- b) subcooling degree and (c-d) superheating degree in low and high temperature circuits $\left(T_{C}=40^{\circ} \mathrm{C}, T_{E}=-50^{\circ} \mathrm{C}, \Delta T_{\text {Cascond }}=5^{\circ} \mathrm{C}, T_{C A S, E}=-5^{\circ} \mathrm{C}\right)$ 


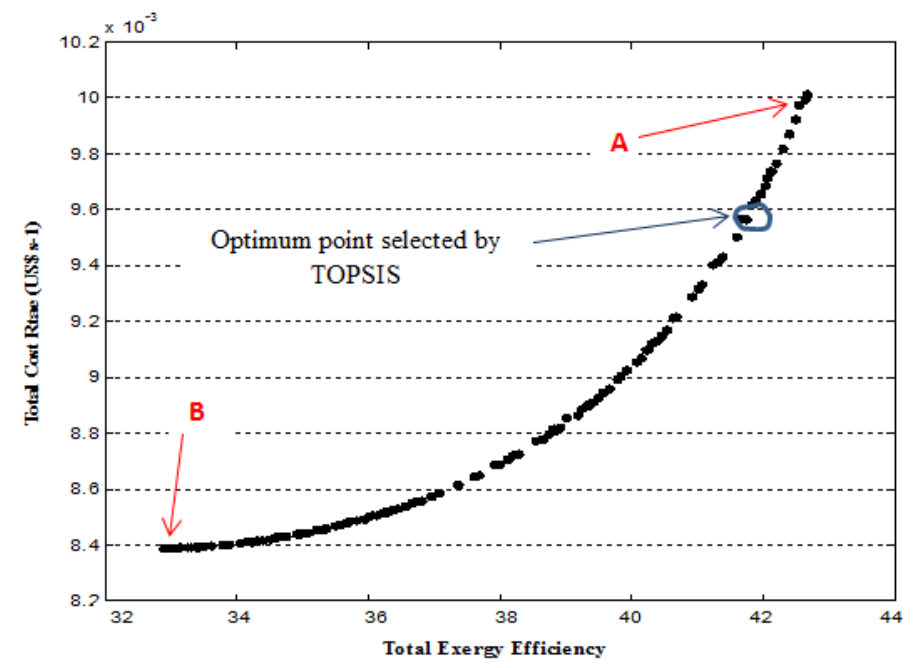

Figure 8. Pareto optimal frontier from multi-objective optimization of R134A/R744 CRS.

\section{CONCLUSION}

In the present work, R134a/R744 cascade refrigeration system, based on exergetic, economic, environmental, and sensitive analysis (3ES) was modeled and analyzed. A multi-objective optimization was also done regarding the Pareto frontier employing NSGA-II optimization and a decision-making strategy. The findings showed that by enhancing $\Delta T_{s u b, L}$ or $\Delta T_{s u b, H}$, the exergetic efficiency and the total annual cost of the CRS increased. Furthermore, according to single objective optimizations, the exergetic efficiency increased by $94.8 \%$, resulting from $38.7 \%$ decrease in the total cost, using the exergetic optimization, in comparison to the base design. The total system cost decreased by $10.3 \%$, using the cost optimization, and the exergetic efficiency increased by $20.6 \%$. The higher cost of air-cooled condenser was achieved for lower values of $T_{E}$ since the logarithmic temperature variation between the condensation and ambient temperatures decreased. However, the cost of the LT compressor decreased because of the decrease in the LTC pressure ratio. The cost of air-cooled condenser decreased because of a decline in the removed heat from the condenser, and consequently, the cost of cascade condenser increased. The findings of multi-objective optimization demonstrated that the exergetic efficiency and the overall annual system expense increased $99.5 \%$ and $28.6 \%$, respectively, and $46.6 \%$ higher energy was saved in both compressors.

\section{REFERENCES}

[1] Getu, H. M., Bansal, P. K. (2006). Simulation model of a low-temperature supermarket refrigeration system. HVAC\&R Research, 12(4), 1117-1139.

[2] Getu, H. M., Bansal, P. K. (2008). Thermodynamic analysis of an R744-R717 cascade refrigeration system. International journal of refrigeration, 31(1), 45-54.

[3] Messineo, A. (2012). R744-R717 cascade refrigeration system: performance evaluation compared with a HFC two-stage system. Energy Procedia, 14, 56-65.

[4] Pearson, A. (2001). New developments in industrial refrigeration. Ashrae Journal, 43(3), 54.

[5] Devotta, S., Padalkar, A. S., Sane, N. K. (2005). Performance assessment of HC-290 as a drop-in substitute to HCFC-22 in a window air conditioner. International Journal of Refrigeration, 28(4), 594-604.

[6] Chen, W. (2008). A comparative study on the performance and environmental characteristics of R410A and R22 residential air conditioners. Applied thermal engineering, 28(1), 1-7.

[7] Lee, T. S., Liu, C. H., Chen, T. W. (2006). Thermodynamic analysis of optimal condensing temperature of cascade-condenser in CO2/NH3 cascade refrigeration systems. International Journal of Refrigeration, 29(7), 1100-1108.

[8] Bhattacharyya, S., Bose, S., Sarkar, J. (2007). Exergy maximization of cascade refrigeration cycles and its numerical verification for a transcritical CO2-C3H8 system. International Journal of Refrigeration, 30(4), 624632.

[9] Mafi, M., Naeynian, S. M., Amidpour, M. (2009). Exergy analysis of multistage cascade low temperature refrigeration systems used in olefin plants. International journal of refrigeration, 32(2), 279-294. 
[10] Keshtkar, M. M., Talebizadeh, P. (2017). Multi-objective optimization of cooling water package based on 3E analysis: A case study. Energy, 134, 840-849.

[11] Rahdar, M. H., Heidari, M., Ataei, A., Choi, J. K. (2016). Modeling and optimization of R-717 and R-134a ice thermal energy storage air conditioning systems using NSGA-II and MOPSO algorithms. Applied Thermal Engineering, 96, 217-227.

[12] Najjar, Y. S., Abubaker, A. M. (2017). Thermoeconomic analysis and optimization of a novel inlet air cooling system with gas turbine engines using cascaded waste-heat recovery. Energy, 128, 421-434.

[13] Rezayan, O., Behbahaninia, A. (2011). Thermoeconomic optimization and exergy analysis of CO2/NH3 cascade refrigeration systems. Energy, 36(2), 888-895.

[14] Raja, B. D., Jhala, R. L., Patel, V. (2018). Multiobjective thermo- economic and thermodynamics optimization of a plate-fin heat exchanger. Heat Transfer-Asian Research, 47(2), 253-270.

[15] Dubey, A. M., Kumar, S., Agrawal, G. D. (2014). Thermodynamic analysis of a transcritical CO2/propylene (R744-R1270) cascade system for cooling and heating applications. Energy conversion and management, 86, 774-783.

[16] Parekh, A. D., Tailor, P. R., Sutaria, N. (2012). Thermoeconomic Optimization of Cascade Refrigeration System using Refrigerant Pair R404A-R508B. In Applied Mechanics and Materials (Vol. 110, pp. 677-684). Trans Tech Publications.

[17] Keshtkar, M. M. (2016). Effect of subcooling and superheating on performance of a cascade refrigeration system with considering thermo-economic analysis and multi-objective optimization. Journal of Advanced Computer Science and Technology, 5(2), 42-47.

[18] Toghyani, S., Kasaeian, A., Ahmadi, M. H. (2014). Multi-objective optimization of Stirling engine using non-ideal adiabatic method. Energy Conversion and Management, 80, 54-62.

[19] Sadatsakkak, S. A., Ahmadi, M. H., Ahmadi, M. A. (2015). Optimization performance and thermodynamic analysis of an irreversible nano scale Brayton cycle operating with Maxwell-Boltzmann gas. Energy Conversion and Management, 101, 592-605.

[20] Kaushik, S. C., Kumar, R., Arora, R. (2016). Thermo-economic optimization and parametric study of an irreversible regenerative Brayton cycle. Journal of Thermal Engineering (ICES2015).

[21] Heidarnejad, P. (2017). Exergy Based Optimization of a Biomass and Solar Fuelled CCHP Hybrid Seawater Desalination Plant. Journal of Thermal Engineering, 3(1), 1034-1043.

[22] Keshtkar, M. M. (2017). Performance analysis of a counter flow wet cooling tower and selection of optimum operative condition by MCDM-TOPSIS method. Applied Thermal Engineering, 114, 776-784.

[23] Wouagfack, P. A. N., Tchinda, R. (2011). Irreversible three-heat-source refrigerator with heat transfer law of $\mathrm{Q} \alpha \Delta(\mathrm{T}-1)$ and its performance optimization based on ECOP criterion. Energy Systems, 2(3-4), 359-376.

[24] Kotas, T. J. (1986). Exergy method of thermal and chemical plant analysis. Trans IChemE, 64, 212-229.

[25] Bejan, A., Tsatsaronis, G., Moran, M., Moran, M. J. (1996). Thermal design and optimization. John Wiley \& Sons.

[26] Aminyavari, M., Najafi, B., Shirazi, A., Rinaldi, F. (2014). Exergetic, economic and environmental (3E) analyses, and multi-objective optimization of a $\mathrm{CO} 2 / \mathrm{NH} 3$ cascade refrigeration system. Applied Thermal Engineering, 65(1-2), 42-50.

[27] Rao, R. V., Saroj, A. (2018). Multi-objective design optimization of heat exchangers using elitist-Jaya algorithm. Energy Systems, 9(2), 305-341.

[28] Klein, S. A., Alvarado, F. L. (1992). EES: Engineering equation solver for the Microsoft Windows operating system. F-Chart software.

[29] Nellis, G., Klein, S. (2009). Mass transfer. Heat Transfer, Cambridge University Press, New York.

[30] Kays, W.M., London, A.L., “Compact Heat Exchangers”, Krieger Publishing Company, (1984).

[31] Shah, R.K., Sekulic, D.P., "Fundamentals of Heat Exchanger Design", Wiley, (2003)

[32] Thirumaleshwar, M., "Software Solutions to Problems on Heat Transfer - Boiling and Condensation", (2013)

[33] Harrell Jr, F. E. (2015). Regression modeling strategies: with applications to linear models, logistic and ordinal regression, and survival analysis. Springer.

[34] Konak, A., Coit, D. W., Smith, A. E. (2006). Multi-objective optimization using genetic algorithms: A tutorial. Reliability Engineering \& System Safety, 91(9), 992-1007.

[35] Holland, J. H. (1992). Adaptation in natural and artificial systems: an introductory analysis with applications to biology, control, and artificial intelligence. MIT press. 